\title{
Posterior implant removal in patients with thoracolumbar spine fractures: long-term results
}

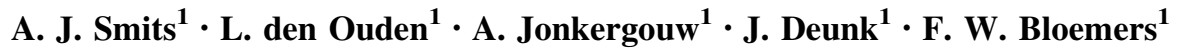

Received: 24 May 2016/Revised: 30 October 2016/Accepted: 13 November 2016/Published online: 18 November 2016

(C) The Author(s) 2016. This article is published with open access at Springerlink.com

\begin{abstract}
Purpose Debate remains whether posterior implants after thoracolumbar spine fracture stabilization should be removed routinely or only in symptomatic cases. Implant related problems might be resolved or even prevented but removal includes secondary risks. The aim of this study was to evaluate safety, patient satisfaction and quality of life after implant removal.

Methods A retrospective cohort study was performed concerning 102 patients that underwent posterior implant removal after stabilization of a traumatic thoracolumbar fracture between 2003 and 2015. Patients were invited to fill in SF-36, EQ-5D and RMDQ questionnaires after implant removal. Additionally, questions concerning satisfaction were presented. Cobb angles before and after removal were measured and in- or decrease of symptoms was gathered from hospital charts.

Results Mean age at removal was 38 years and time from implant removal to questionnaire was approximately 7 years, 62 patients filled in the questionnaires. Complications were present in $8 \%$ and quality of life was reported as fairly good. Patients had less back pain related disability compared to chronic low back pain patients. After removal there was a kyphosis increase which did not correspond with worsened clinical outcome. Removal decreased most symptoms and even asymptomatic patients reported benefit in most cases. An increase of symptoms after removal was reported in $11 \%$ of patients.
\end{abstract}

\section{A. J. Smits}

aj.smits@vumc.nl

1 Department of Traumasurgery, VU University Medical Centre, De Boelelaan 1117, room 7F020, 1081 HV Amsterdam, The Netherlands
Conclusion Implant removal is generally safe and provides high patient satisfaction. Overall, patients have a fairly good quality of life. Most symptomatic and asymptomatic patients report benefit from removal. However, low risks of complications and increase of symptoms have to be weighted for individual patients.

Keywords Thoracolumbar fracture - Posterior implant . Implant removal · Quality of life

\section{Introduction}

Treatment of thoracolumbar spine fractures depends on fracture morphology, the presence of ligamentous injury and neurological deficit. While surgical stabilization with posterior pedicle screws and rods is clearly indicated for unstable fractures with ligamentous injury and neurological deficit, operative and non-operative treatment varies for most fractures [1]. In addition, surgical procedures such as transpedicular bone grafting and fusion are also subject to global variability.

The use of metal implants establishes immediate stability and spinal anatomy restoration, thereby preventing neurologic deterioration and minimizing pain [2-4]. This allows early mobilization, consequently improving the rehabilitation process of the patient and reducing postoperative complications, such as pulmonary infections and decubitus [3-5]. During the last decades the instrumentation and approaches of surgical treatment underwent numerous developments [4, 6-8].

When fracture consolidation is present, posterior implants have become dispensable [9]. Possible concerns of in situ implants are thought to be disc degeneration, facet arthrosis, micromotion, metal fretting, infections and 
osteopenia caused by stress shielding [9-13]. On the contrary, removing the implant is accompanied with risks such as surgical site infection, neurovascular injury, loss of reduction and refracture $[10,14,15]$. So far, there is no unanimity about the necessity and timing of the removal of implants.

Previous studies on implant removal focused merely on removal after surgery for deformity correction and low back pain, or only described results of implant removal because of implant related symptoms [9, 12, 14-17]. Some described only small cohorts [2, 4, 16] or focused largely on removal of long-segment fixation [10]. Other studies focused on the posterior stabilization itself, but advocated routine removal of implants to regain mobility of the spine and minimize potential damage $[4,18]$. In the current literature there is no consensus whether implants should be removed routinely after fracture consolidation, or only in selected cases with pain or other implant related symptoms.

The aim of this study was to evaluate safety, patient satisfaction, quality of life and back specific outcomes after posterior implant removal for traumatic thoracolumbar fractures in both symptomatic and asymptomatic patients.

\section{Materials and methods}

A retrospective cohort study was performed with adjacent data collection concerning patients' current situation. The study was reported following the STROBE-statement for observational studies. Patients were retrieved from the hospital system by specific surgery implant removal codes. Inclusion only consisted of patients that underwent posterior implant removal after posterior or combined anteroposterior stabilization of one or more traumatic thoracolumbar (Th3-L5) fractures between 2003 and 2015 in our university level 1 trauma center. Patients had originally been surgically stabilized because of fracture deformity, ligamentous injury or neurological deficit. Not all patients that underwent surgical stabilization in this period underwent implant removal, this was generally based on preference of treating surgeon or on reported symptoms. Requirements for implant removal were: (1) approximately 1 year after surgical stabilization, (2) confirmed fracture consolidation on CT or conventional radiography (3) patients' informed consent concerning the risks of surgery. Criteria for exclusion were: age below 18, complete spinal cord injury and implant removal because of deep infection of implants.

\section{Data collection and clinical follow-up}

Patients' baseline characteristics at primary injury were collected from the trauma registry and hospital information system. These included age, sex, mechanism of injury, level of injury, amount of fractured vertebrae, neurologic status, injury severity score (ISS), surgical treatment, implants used, amounts of segments fused, date and duration of admissions and complications. Neurologic injury was scored according to the AO-spine neurologic modifier [19]. Outpatient hospital charts were reviewed to gather further information about complications and the amount of symptoms before and after implant removal. Three groups could be created based on symptoms: (1) the asymptomatic group; no reported symptoms at all before implant removal, (2) the symptomatic group; pain or implant-specific symptoms before removal and (3) the unknown group; unclear whether symptoms were present prior to removal. Additionally, hospital charts were reviewed whether symptoms increased, decreased or remained unchanged after implant removal.

All patients were invited to fill out three validated questionnaires in the context of this study; the short-form 36 (SF-36), Euroquol 5 dimensions (EQ-5D), Roland Morris Disability Questionnaire (RMDQ) [20] and a demographic questionnaire. The demographic questionnaire focused on patients' opinion about the removal of the posterior implant concerning experienced benefit and satisfaction gained after removal. These were answered on a three level scale (a lot, some or none). As a final question, patients were asked if they would hypothetically undergo the same procedure again (yes, no or don't know).

\section{Fracture morphology and radiographic follow-up}

In all patients the available radiographic material after injury was reassessed for fracture classification. This was done following the 2013 AO-spine fracture classification [19]. Each fracture was classified by two separate authors using CT-scans, MRI when available and the surgeon's perioperative report to objectify damage to the posterior ligamentous complex (PLC) or anterior ligamentous complex. A consensus meeting took place with two experienced spine trauma surgeons about the cases on which debate existed. Cobb angles [21] were measured on sagittal CT when available or on lateral plain radiographs or sagittal-MRI, kyphosis was noted as a positive value and lordosis as negative. Measurements were done at time of injury, implant removal, 1 year after implant removal and at final follow-up if available.

\section{Surgical technique}

The initial fracture treatment consisted of solely posterior open stabilization or combined anterior and posterior stabilization. No patients were treated with percutaneous techniques, all posterior implants consisting of pedicle 
screws and rods were inserted through an open approach, no posterior fusion was performed. Additional anterior stabilization was performed in a second procedure only in selective cases, based on a load sharing classification score of $\geq 7$ [22] and clinical condition. Anterior stabilization consisted of an expandable titanium cage which was inserted after a corpectomy and disc removal. The corpectomy bone was mixed with demineralized bone matrix and added around the cage, subsequently additional anterolateral plating was performed. The procedure of anterior stabilizations was performed either open or thoracoscopically depending on the level of the fracture. In one patient, balloon kyphoplasty was performed in addition to posterior stabilization.

Posterior implant removal was carried out with the patient in prone position through an open approach with midline incision. No prophylactic antibiotics were given during implant removal. Wound drains were left behind and removed when output ceased. Post-operatively, patients were allowed to mobilize as tolerated.

\section{Statistical analysis}

Continuous data is shown as mean with standard deviation (SD), or if applicable median with interquartile range (25th-75th percentile). Categorical data are shown as numbers and percentages. To compare categorical dichotomous variables a Chi-square test with absolute frequencies was used. To compare continuous data with normal distribution a $t$ test was used. To compare variables over time a paired $t$ test was used. Possible correlations were tested with a $t$ test for two subgroups. In the case of more subgroups ANOVA and a scatterplot with Pearson or Spearman correlation, dependent on normality, were used. To test ordinal variables a Mann-Whitney test was used in the case of two groups, and a Kruskal-Wallis in the case of more groups. Effect modification was tested with stratified analysis. The SF-36 is not normally distributed [23] and neither was the RMDQ in our sample, but in consistency with previous literature $[24,25]$ and to be able to compare the values to a Dutch population, means with SD were used. $P<0.05$ was regarded as statistically significant. Statistical analysis was conducted using IBM SPSS 22.0.

\section{Results}

One hundred and two consecutive patients were included in this study after posterior implant removal. The mean age was 38 years (range 18-78). Implant removal was done after a median of 12 months (IQR 10-14) after fracture surgery. The questionnaires were filled out after a mean of 6 years and 10 months (SD 43) after implant removal.
Sixty-one percent had an A3 fracture, $41 \%$ had a B-type fracture and $6 \%$ had a C-type fracture. Sixty-four patients $(63 \%)$ underwent solely posterior fixation and 38 patients (37\%) underwent combined anterior-posterior stabilization. Sixty-two patients $(61 \%)$ responded to our invitation to fill out the questionnaires, of these patients 59 valid outcome scores could be calculated. The asymptomatic, symptomatic and unknown group, respectively, consisted of $28(28 \%), 59(58 \%)$ and $15(15 \%)$ patients. Further baseline characteristics and treatment modalities are shown in Table 1.

There were eight (8\%) implant removal-related complications (Table 2), from which wound infections were most prominent. Two deep wound infections were treated with re-admission, drainage and intravenous antibiotics. Superficial infections could be treated with oral antibiotics without admission. One symptomatic patient, with a consolidated fracture on $\mathrm{CT}$, experienced progressive pain after implant removal due to end plate deformity without progressive kyphosis. This patient was anterior stabilized through a minimally invasive thoracoscopic approach 10 months after implant removal with good result.

Complications were not correlated with worse outcome scores (Table 3). Effect modification was tested for ISS $<16$ and $\geq 16$, neurologic injury and posterior vs combined stabilization. ISS was an effect modifier and stratified outcomes are reported. The group with neurologic injury (Neurologic Modifier 2 or 3$)$ was too small $(n=5)$ to draw conclusions on effect modification. Surgical technique (posterior vs combined) caused no change in outcomes.

Compared to the general Dutch population scores on the EQ-5D [26], the majority of patients with an ISS $<16$ did not report more problems on mobility and self-care, but did report increased pain, anxiety and problems on daily activity $(P<0.01)$. Patients with an ISS $\geq 16$ reported more problems on all domains $(P<0.01)$ (Table 4; Fig. 1). On the SF-36 all patients scored worse on pain, vitality and physical component score compared to the general Dutch population [24] $[P<0.05$ (ISS $<16$ ), $P<0.01$ (ISS $\geq 16$ )]. Patients scored less back pain related disability (RMDQ) compared to a Dutch reference population with treated chronic low back pain [25] (ISS $<16: \quad P<0.01, \quad$ ISS $\geq 16: \quad P<0.05$ ) $\quad$ (Table 4; Fig. 2).

The majority of symptomatic and asymptomatic patients experienced some kind of benefit, reported satisfaction and would hypothetically undergo a re-removal (Fig. 3). After removal, $11 \%$ of the total group showed a subjective increase of symptoms (Fig. 4) while these patients did not have removal-related complications. In the asymptomatic group, $74 \%$ reported benefit of the removal and $90 \%$ had no symptoms after removal. The symptomatic patients 
Table 1 Patient characteristics

\begin{tabular}{|c|c|}
\hline$n$ & 102 \\
\hline Sex M:F & $\begin{array}{l}55: 47 \\
\quad(55 \%: 46 \%)\end{array}$ \\
\hline \multicolumn{2}{|l|}{ Mechanism of injury } \\
\hline Fall/jump off height & $42(41 \%)$ \\
\hline Traffic accident & $28(28 \%)$ \\
\hline Conventional fall & $13(13 \%)$ \\
\hline Fall off horse & $9(9 \%)$ \\
\hline Object on back & $7(7 \%)$ \\
\hline Sports accident & $3(3 \%)$ \\
\hline ISS (median, IQR) & $9(4-13)$ \\
\hline \multicolumn{2}{|l|}{ Level of injury ${ }^{a}$} \\
\hline Th3-10 & $12(12 \%)$ \\
\hline Th11-L2 & $77(76 \%)$ \\
\hline L3-L5 & $13(13 \%)$ \\
\hline \multicolumn{2}{|l|}{ AO morphology ${ }^{b}$} \\
\hline $\mathrm{A} 0-\mathrm{A} 2$ & $5(5 \%)$ \\
\hline A3 & $62(61 \%)$ \\
\hline A4 & $35(34 \%)$ \\
\hline B1 & $8(8 \%)$ \\
\hline B2 & $32(31 \%)$ \\
\hline B3 & $2(2 \%)$ \\
\hline $\mathrm{C}$ & $6(6 \%)$ \\
\hline $\begin{array}{l}\text { Patients with multiple vertebral fractures (type: } \\
\text { A/B/C) }\end{array}$ & $41(40 \%)$ \\
\hline \multicolumn{2}{|l|}{ Neurologic modifier (at injury) ${ }^{\mathrm{c}}(n=78)$} \\
\hline N0 & $62(61 \%)$ \\
\hline N1 & $3(3 \%)$ \\
\hline $\mathrm{N} 2$ & $5(5 \%)$ \\
\hline N3 & $7(7 \%)$ \\
\hline Not documented & $25(25 \%)$ \\
\hline \multicolumn{2}{|l|}{ Posterior fixation } \\
\hline USS & $83(81 \%)$ \\
\hline Tenor & $16(16 \%)$ \\
\hline Other (S4, Expedium) & $3(3 \%)$ \\
\hline Combined anterior-posterior fixation & $37(36 \%)$ \\
\hline Thoracoscopic approach & 28 \\
\hline Open approach & 9 \\
\hline Cage & 31 \\
\hline Bone graft & 6 \\
\hline \multicolumn{2}{|l|}{ Posterior segments immobilized } \\
\hline 1 & $1(1 \%)$ \\
\hline 2 & $71(70 \%)$ \\
\hline 3 & $19(19 \%)$ \\
\hline$>3$ & $11(11 \%)$ \\
\hline
\end{tabular}

${ }^{\text {a }}$ Level of injury subjects may overlap total $n$ because some patients suffered multiple vertebral fractures

b AO morphology subjects may overlap total $n$ because most B and C type injuries are associated with an A type fracture

c N4: excluded reported a direct decrease of symptoms in $62 \%$ of cases. Cobb angles increased significantly $(P<0.01)$ after removal of implant until final follow-up with $4.9^{\circ}$ and $3.5^{\circ}$, respectively, for posterior and antero-posterior fixation [median 22 (IQR 12-31) and 26 (IQR 18-47) months] (Table 5; Fig. 5). Subgroup analysis for Cobb angle increase, fracture type and treatment modalities showed no significant correlation coefficients or differences with outcomes (Table 4).

\section{Discussion}

After its introduction in the 1980s, posterior short-segment fixation with pedicle screws became the most widely performed surgical treatment for traumatic spine fractures [6]. However, indications for spinal implant removal after fracture consolidation are not well defined, with different policies being applied in absence of international guidelines. Disadvantages of leaving the implant in situ have been described [9-11], this might lead to pain, functional impairments and implant-induced injury to the spine $[2,4,11,27]$.

Only few previous studies focused on implant removal after thoracolumbar fractures, these concluded a maintained mobility [4], increased range of motion and functional outcome $[2,10,17]$ after implant removal. However, these studies were all retrospective with small cohorts and limited validated outcomes. Recently, Jentzsch et al. [17] reported a decrease in pain and improved function in a cohort after implant removal because of related symptoms. However, the follow-up period was only 6 months and except pain no validated functional outcomes were reported. Moreover, no asymptomatic patients were studied, but only symptomatic patients with discomfort or implant related pain. Jeon et al. [10]. recently described a casecontrol study that compared routine implant removal to a control-group without removal. They concluded that routine removal is beneficial because it alleviates pain and disability. However, the study included merely long-segment fixation (on average four levels) and quality of life was not assessed. In this study, we evaluated short-segment fixation, included posterior and antero-posterior stabilized patients and described quality of life. Additionally we differentiated between asymptomatic and symptomatic removal of implants.

\section{Outcomes}

The average quality of life scored on the EQ-5D after a traumatic fracture with removal of implant in this study is slightly lower compared to a normative population but still considerably high. Other studies focus mainly on radiological outcomes and pain. Patients with an ISS $\geq 16$ 
Table 2 Complications

\begin{tabular}{ll}
\hline Complication & $N(\%)$ \\
\hline Superficial wound infection & $3(3)$ \\
Deep wound infection & $2(2)$ \\
Instability after removal & $1(1)$ \\
Bleeding & $1(1)$ \\
Pneumonia & $1(1)$ \\
Total & $8(8)$ \\
\hline
\end{tabular}

scored worse on all quality of life scores compared to patients with an ISS $<16$, indicating that concomitant injuries probably have a negative impact on quality of life.

Measuring back specific outcome and quality of life is difficult because none of the existing outcome measurements for spinal pathology are validated for spinal trauma $[28,29]$. The RMDQ is widely used in studies that assess spinal trauma, but is only validated for patients with low back pain. Siebenga et al. [30], however, have shown a correlation for VAS and RMDQ in patients with a vertebral fracture, and therefore, we used the RMDQ to assess back function. To assess quality of life we used the EQ-5D and SF-36 which are not validated for spinal trauma [28] but widely used in studies assessing spinal trauma. These questionnaires cover a lot of $\mathrm{CF}$ categories that are deemed relevant for spinal trauma [28, 29].

\section{Safety and satisfaction}

We found removal-related complications in only $8 \%$, with only one of 102 patients that needed a re-operation. Considering this low amount of serious complications, we think that implant removal is generally safe. Overall, it seems that implant removal surgery provides high patient satisfaction. Most patients reported benefit of implant removal and the majority of patients are willing to undergo the same procedure again. Most symptomatic patients had a decrease of symptoms after implant removal and reported benefit. Even in patients that were asymptomatic prior to removal, $74 \%$ still reported some kind of benefit due to implant removal. This benefit might be explained by the fact that implant removal could aid in restoring spinal motion $[2,10,13]$. However, we did not further define this benefit nor did we measure spinal movements in this study. Although the benefits of implant removal on spinal movement are likely, they have not been proven in prospective randomized trials yet and should, therefore, be taken with some caution. While most patients reported benefit and satisfaction, approximately $11 \%$ of the patients

Table 3 Correlations for treatment modalities, fracture classification and radiologic parameters with outcomes

\begin{tabular}{|c|c|c|c|c|c|c|}
\hline Variable & Group & $n$ & EQ-5D Index mean (SD) & SF-36 PCS mean (SD) & RMDQ median (IQR) & $P^{\mathrm{a}}$ \\
\hline $\begin{array}{l}\text { Cobb-angle change from removal to } \\
\text { FFU }\end{array}$ & Continuous & 34 & $\begin{array}{l}\text { Spearman }-0.02 \\
\quad(P=0.9)\end{array}$ & $\begin{array}{l}\text { Pearson }-0.1 \\
\quad(P=0.7)\end{array}$ & $\begin{array}{l}\text { Spearman } 0.06 \\
\quad(P=0.7)\end{array}$ & NS \\
\hline \multirow[t]{3}{*}{ Fracture level } & T3-T10 & 7 & $0.76(0.11)(P=0.2)^{\dagger}$ & $40.8(11)(P=0.6)$ & $5.00(9)(P=0.8)^{\circ}$ & NS \\
\hline & $\mathrm{T} 11-\mathrm{L} 2$ & 45 & $0.83(0.17)$ & $45.5(13)$ & $2.00(9)$ & \\
\hline & L3-L5 & 6 & $0.70(0.15)$ & $42.1(9)$ & $7.00(8)$ & \\
\hline \multirow[t]{2}{*}{ Time to implant removal (months) } & $\leq 10$ & 14 & $0.80(0.14)(P=0.8)^{\sim}$ & $47.2(10)(P=0.5)^{\sim}$ & $1.50(9)(P=0.6)^{*}$ & NS \\
\hline & $>10$ & 41 & $0.81(0.19)$ & $44.8(12)$ & $3.00(6)$ & \\
\hline \multirow[t]{3}{*}{ AO morphology } & A3-A4 & 30 & $0.84(0.12)(P=0.2)^{\dagger}$ & $45.2(12)(P=0.9)^{\dagger}$ & $2.00(7)(P=0.6)^{\circ}$ & NS \\
\hline & $\mathrm{B}$ & 24 & $0.78(0.21)$ & $44.5(12)$ & $4.00(11)$ & \\
\hline & $\mathrm{C}$ & 4 & $0.71(0.19)$ & $42.8(15)$ & $2.00(15)$ & \\
\hline \multirow[t]{2}{*}{ Stabilization } & $\mathrm{P}$ & 30 & $0.79(0.20)(P=0.4)^{\sim}$ & $44.7(12)(P=1.0)^{\sim}$ & $3.00(6)(P=0.7)^{*}$ & NS \\
\hline & AP & 28 & $0.83(0.13)$ & $44.7(13)$ & $2.50(12)$ & \\
\hline \multirow[t]{3}{*}{ Segments fixated } & 2 & 42 & $0.81(0.19)(P=0.9)^{\dagger}$ & $45.6(12)(P=0.08)^{\dagger}$ & $2.00(8)(P=0.6)^{\circ}$ & NS \\
\hline & 3 & 9 & $0.81(0.13)$ & $46.5(12)$ & $4.00(9)$ & \\
\hline & $\geq 4$ & 7 & $0.79(0.06)$ & $34.2(12)$ & $5.00(9)$ & \\
\hline \multirow[t]{2}{*}{ Complications } & Yes & 2 & $0.82(0.17)(P=0.9)^{\sim}$ & $48.0(3)(P=0.7)^{\sim}$ & $3.50(-)(P=0.7)^{*}$ & NS \\
\hline & No & 56 & $0.81(0.77)$ & $44.6(12)$ & $3.00(9)$ & \\
\hline
\end{tabular}

FFU final follow-up, $N S$ not significant, $P C S$ physical component score, $P$ posterior, $A P$ antero-posterior

$\dagger$ One way ANOVA

${ }^{\circ}$ Kruskal-wallis test

$\sim$ Independent $t$ test

* Mann-whitney

${ }^{\text {a }}$ Composed over-all significance 
Table 4 Outcome scores for quality of life and back pain related disability stratified for ISS $<$ and $\geq 16$

\begin{tabular}{|c|c|c|c|c|c|c|c|}
\hline \multicolumn{3}{|c|}{ Clinical follow-up stratified for ISS } & \multirow{2}{*}{ ISS $<16(n=46)$} & \multirow[t]{2}{*}{ ISS $>16(n=13)$} & \multirow[t]{2}{*}{ Dutch population $[24,26]$} & \multicolumn{2}{|l|}{$P$} \\
\hline & & & & & & ISS $<16$ & ISS $>16$ \\
\hline \multirow[t]{12}{*}{ EQ-5D } & \multirow[t]{2}{*}{ Mobility $^{\dagger}$} & No problems & $83 \%$ & $42 \%$ & $87 \%$ & \multirow[t]{2}{*}{0.4} & \multirow[t]{2}{*}{$<0.01 *$} \\
\hline & & Problems & $17 \%$ & $58 \%$ & $13 \%$ & & \\
\hline & \multirow[t]{2}{*}{ Self-care ${ }^{\dagger}$} & No problems & $91 \%$ & $75 \%$ & $96 \%$ & \multirow[t]{2}{*}{0.08} & \multirow[t]{2}{*}{$0.01 *$} \\
\hline & & Problems & $9 \%$ & $25 \%$ & $4 \%$ & & \\
\hline & \multirow[t]{2}{*}{ Usual activity $^{\dagger}$} & No problems & $54 \%$ & $50 \%$ & $87 \%$ & \multirow[t]{2}{*}{$<0.01 *$} & \multirow[t]{2}{*}{$<0.01 *$} \\
\hline & & Problems & $46 \%$ & $50 \%$ & $13 \%$ & & \\
\hline & \multirow[t]{2}{*}{ Pain/discomfort ${ }^{\dagger}$} & No problems & $29 \%$ & $8 \%$ & $66 \%$ & \multirow[t]{2}{*}{$<0.01 *$} & \multirow[t]{2}{*}{$<0.01 *$} \\
\hline & & Problems & $71 \%$ & $92 \%$ & $34 \%$ & & \\
\hline & \multirow[t]{2}{*}{ Anxiety/depression ${ }^{\dagger}$} & No problems & $72 \%$ & $58 \%$ & $97 \%$ & \multirow[t]{2}{*}{$<0.01 *$} & \multirow[t]{2}{*}{$<0.01 *$} \\
\hline & & Problems & $28 \%$ & $42 \%$ & $3 \%$ & & \\
\hline & $\mathrm{VAS}^{\circ}$ & $N=58$ & 76 (SD 15) & & 82 (SE 0.4) & $<0.01^{*}$ & \\
\hline & Index value ${ }^{\circ}$ & $N=58$ & $0.81(\mathrm{SD} 0.17)$ & & $0.910($ SE 0.005$)$ & $<0.01^{*}$ & \\
\hline \multirow[t]{10}{*}{$\mathrm{SF}-36^{\circ}$} & \multicolumn{2}{|l|}{ Physical function } & 79 (SD 24) & 64 (SD 24) & $83($ SD 22.8) & 0.3 & $0.03 *$ \\
\hline & \multicolumn{2}{|l|}{ Role physical } & 66 (SD 43) & 41 (SD 42) & 76 (SD 36.3) & 0.1 & $0.02 *$ \\
\hline & \multicolumn{2}{|l|}{ Bodily pain } & 64 (SD 27) & $52(\mathrm{SD} 21)$ & 75 (SD 23.4) & $<0.01^{*}$ & $<0.01 *$ \\
\hline & \multicolumn{2}{|l|}{ General health } & 67 (SD 26) & 55 (SD 29) & 71 (SD 20.7) & 0.3 & 0.1 \\
\hline & \multicolumn{2}{|l|}{ Vitality } & $61(\mathrm{SD} 21)$ & $52(\mathrm{SD} 23)$ & 69 (SD 19.3) & $<0.01^{*}$ & $0.02 *$ \\
\hline & \multicolumn{2}{|l|}{ Social functioning } & 75 (SD 29) & 68 (SD 23) & $84(\mathrm{SD} 22.4)$ & 0.05 & $0.02 *$ \\
\hline & \multicolumn{2}{|l|}{ Emotional } & 76 (SD 39) & 70 (SD 44) & 82 (SD 32.9) & 0.3 & 0.3 \\
\hline & \multicolumn{2}{|l|}{ Mental health } & 78 (SD 18) & 69 (SD 24) & 77 (SD 17.4) & 0.8 & 0.2 \\
\hline & \multicolumn{2}{|c|}{ Physical component score } & 46 (SD 12) & 38 (SD 12) & $50(\mathrm{SD} 10.0)$ & $0.04 *$ & $<0.01^{*}$ \\
\hline & \multicolumn{2}{|c|}{ Mental component score } & 49 (SD 11) & 48 (SD 13) & $50(\mathrm{SD} 10.0)$ & 0.6 & 0.5 \\
\hline
\end{tabular}

Treated chronic low back pain [25]

\begin{tabular}{|c|c|c|c|}
\hline $\mathrm{RMDQ}^{\circ}$ & $5.1(\mathrm{SD} 5.7)$ & 10.9 (SD 5.3) & $<0.001 *$ \\
\hline
\end{tabular}

EQ5D dichotomized scores: 1 (no problems), 2-5 (problems). EQ-5D VAS; current health 1-100 (100 maximum health). EQ-5D index value; 0 (death), 1 (full health). SF-36 domains 1-100 (100 maximum health). Aggregated physical and mental component scores; standardized scores weighted for the Dutch population with mean 50 (SD 10). RMDQ; 0-24 (24 maximum back pain related disability)

* Denotes a significant difference $(P<0.05)$ compared to, respectively, the Dutch population or low back pain group

$X^{2}$ test

$\circ$ One-sample $t$ test

had increased symptoms after removal, irrespective of asymptomatic or symptomatic. We think that the small chance of $8 \%$ surgical complications and $11 \%$ chance of increase of symptoms should, therefore, be weighted in individual patients, especially in patients without symptoms prior to removal. In people with implant-specific symptoms and pain prior to removal, implant removal seems to be indicated while it decreased these symptoms in the majority of patients. The benefits of removal in symptomatic patients seem to outweigh the low risk of surgical complications and increase after removal.

\section{Kyphosis and correlations}

We found a significant increase in kyphosis after implant removal and over time a small but significant correction loss, which was irrespective of fixation type. Only the combined procedure is able to maintain some kyphosis correction from injury to final follow-up, even after posterior implant removal. This is probably due to the fusion performed during anterior stabilization, while no fusion was performed during solely posterior stabilization. Previous studies reported conflicting outcomes after posterior implant removal, ranging from no $[17,18]$ to significant loss of correction [6,31]. Different studies are hard to compare while different follow-up times and surgical techniques are used. More importantly, clinical outcome does not seem to be correlated with loss of correction. We found no significant correlation between Cobb angle increase and outcome scores, which is in correspondence with previous literature $[4,27,32,33]$. The three to five degree correction loss was statistically significant but does 
Fig. 1 Amount of patients that reported problems on the different EQ-5D-5L domains compared to the Dutch population. Asterisk denotes a significant difference compared to the Dutch population $(P<0.05)$
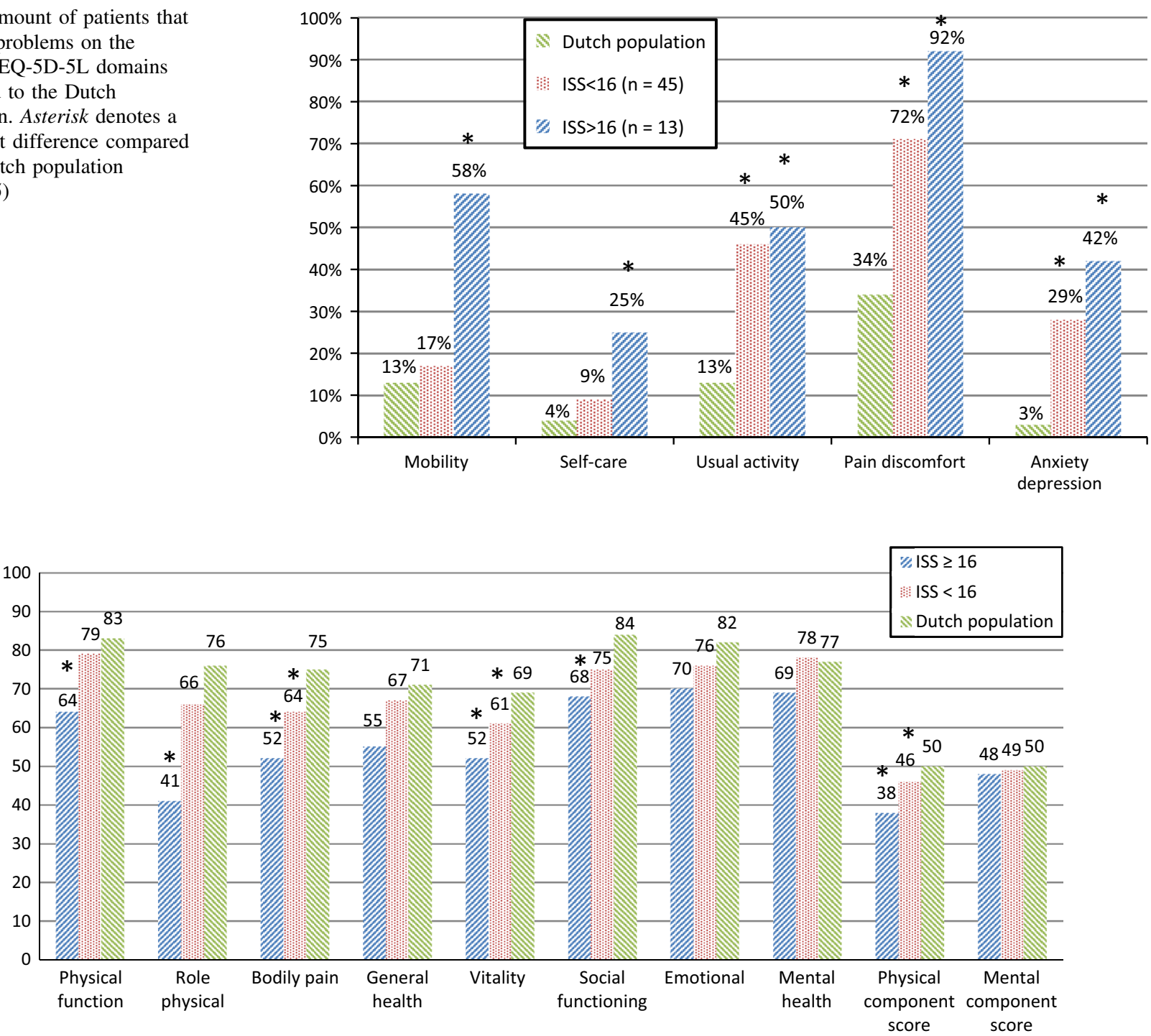

Fig. 2 Stratified SF-36 scores compared to the Dutch population. Asterisk denotes a significant difference compared to the Dutch population $(P<0.05)$

not seem clinically relevant. Loss of correction is, therefore, not a valid argument against implant removal. Some authors argue that implant removal within 10 months provides a better range of motion [2, 4], and therefore, possibly better functional outcome. However, in our study we did not find a correlation between outcome scores and time to implant removal.

\section{Minimally invasive techniques}

Although no patients in this study were treated with percutaneous techniques, this approach is increasingly applied for posterior instrumentation [7, 8]. Also minimally invasive balloon or stenting kyphoplasty is suggested as an alternative for anterior stabilization [7]. While the mediumterm results in a selected group seems satisfying [7], it remains unclear whether this construct provides stability comparable to a titanium cage with additional lateral plating, especially in fractures with a LSC $\geq 7$. An interesting scope for future research would be the removal of percutaneously inserted posterior implants. The technique is promising in terms of blood loss and operation time [8], but there are currently no studies specifically on removal after percutaneous fixation. In patients that underwent additional balloon kyphoplasty [7], the question is whether the injected cement still provides enough support to the anterior column after posterior implant removal.

\section{Limitations}

A limitation to our study is the retrospective nature. We did not have quality of life and back specific function measures 


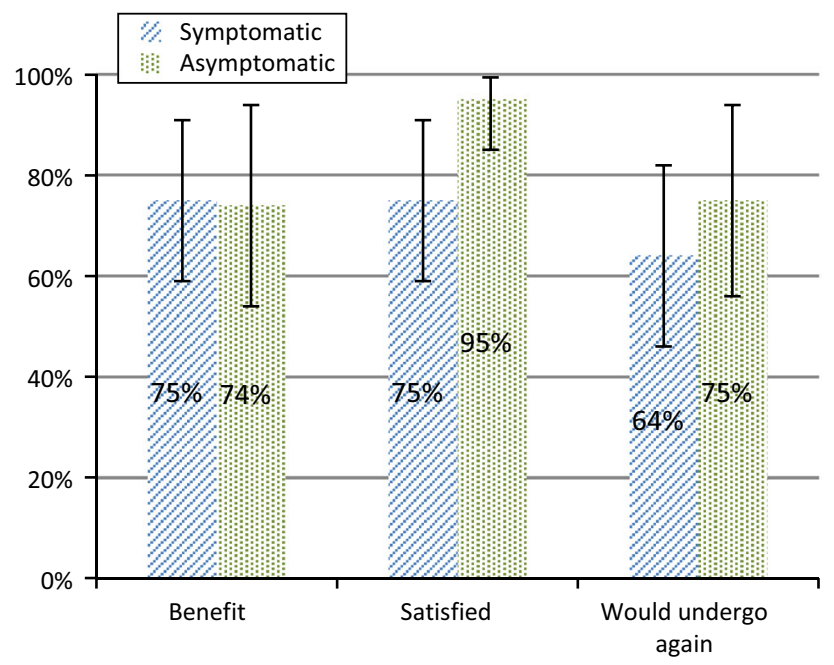

Fig. 3 Satisfaction and benefit of implant removal for asymptomatic and symptomatic group (with 95\% CI's). Ratios of patients that answered yes (from yes, no or don't know) on questionnaire

prior to implant removal. Therefore, we cannot draw validated conclusions concerning in- or decrease in quality of life and back specific function after implant removal. Moreover, we did not have a control-group with patients in whom implants were not removed, so conclusions about long-term outcomes with and without removal cannot be drawn. Although many implants were routinely removed in asymptomatic patients, still a selection bias may have occurred concerning the decision for implant removal. In addition, it is possible that some patients who underwent implant removal were not retrieved, and therefore, not included in this study. Our response rate of $60 \%$ was relatively high for questionnaires concerning quality of life outcomes [34], but very unsatisfied or very satisfied patients could have been more prone to return the questionnaires. Possible explanations for the non-responders could be outdated contact data after a long period of follow-up (mean $>6$ years) and a psychiatric history (with a jump from height) which might make patients less likely to respond to the questionnaires. Although hospital charts, hospital information system and trauma registry were all thoroughly investigated, some data were missing. Radiographic follow-up was done following local protocols in
Table 5 Cobb angles at different times for respective surgery types

\begin{tabular}{lllll}
\hline Group & $n$ & CA at injury & CA at removal & \\
\hline P & 50 & 6.7 (SD 10) & 8.0 (SD 10) & $P=0.29$ \\
AP & 33 & 15.6 (SD 11) & 11.3 (SD 14) & $P=0.02^{*}$ \\
\hline Group & $n$ & CA at removal & CA at FFU & \\
\hline P & 22 & 7.5 (SD 9) & 12.4 (SD 9) & $P<0.001^{*}$ \\
AP & 25 & 9.9 (SD 12) & 13.4 (SD 14) & $P<0.01^{*}$
\end{tabular}

$P$ solely posterior stabilization, $A P$ antero-posterior stabilization, $C A$ cobb angle, $F F U$ final follow-up

* Denotes a significant difference (paired samples $t$ test)

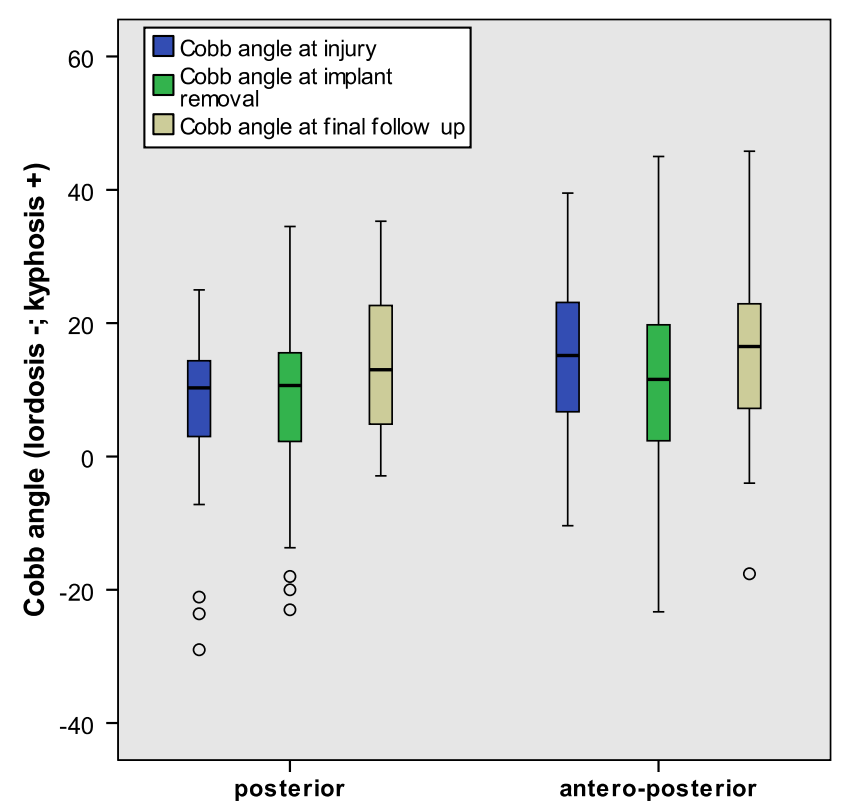

Fig. 5 Cobb angles at different times for solely posterior and anteroposterior instrumentation

supine position so that kyphosis angles are probably slightly underestimated. Cobb-angles were generally measured on sagittal CT at injury and on plain radiograph at follow-up which could have caused some inaccuracy. Change in cobb-angle though is probably fairly accurate, but might not be sufficient to translate to kyphosis in standing position.
Fig. 4 Evolution of symptoms after removal for a asymptomatic group $(n=21)$ and $\mathbf{b}$ symptomatic group $(n=50)$
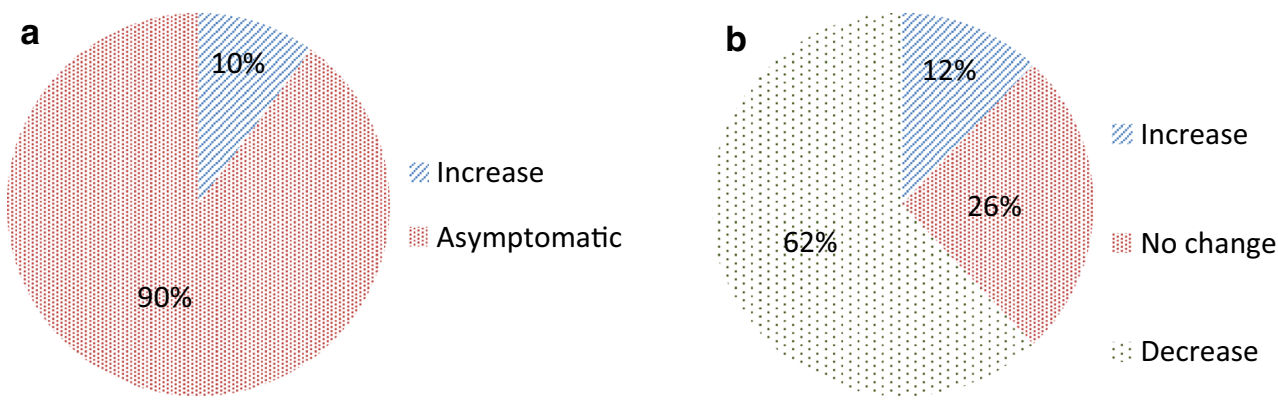


\section{Conclusion}

Good quality of life and patient satisfaction are reported after posterior implant removal. Patients have little residual low back pain related disability and the surgical complication rate after removal is low. In most symptomatic patients, implant removal directly decreases symptoms. Most patients that are asymptomatic prior to removal also experience benefit from the removal. On the other hand, a small amount of patients experience an increase of symptoms after removal. Risks of surgical complications and increase of symptoms should be weighted for every patient.

\section{Compliance with ethical standards}

Ethical approval This study was approved by the medical ethical committee METc VUmc under case number 2014.488.

Conflict of interest All authors declare they have nothing to disclose that could potentially bias or influence this work.

Open Access This article is distributed under the terms of the Creative Commons Attribution 4.0 International License (http://crea tivecommons.org/licenses/by/4.0/), which permits unrestricted use, distribution, and reproduction in any medium, provided you give appropriate credit to the original author(s) and the source, provide a link to the Creative Commons license, and indicate if changes were made.

\section{References}

1. Abudou M, Chen X, Kong X, Wu T (2013) Surgical versus nonsurgical treatment for thoracolumbar burst fractures without neurological deficit. Cochrane Database Syst Rev. doi:10.1002/ 14651858.CD005079.pub3

2. Kim HS, Kim SW, Ju CI, Wang HS, Lee SM, Kim DM (2014) Implant removal after percutaneous short segment fixation for thoracolumbar burst fracture: does it preserve motion? J Korean Neurosurg Soc 55:73-77. doi:10.3340/jkns.2014.55.2.73

3. Dai LY, Jiang SD, Wang XY, Jiang LS (2007) A review of the management of thoracolumbar burst fractures. Surg Neurol 67:221-231. doi:10.1016/j.surneu.2006.08.081 (discussion 231)

4. Yurac R, Marre B, Urzua A, Munjin M, Lecaros MA (2006) Residual mobility of instrumented and non-fused segments in thoracolumbar spine fractures. Eur Spine J Off Publ Eur Spine Soc Eur Spinal Deform Soc Eur Sect Cerv Spine Res Soc 15:864-875. doi:10.1007/s00586-005-0939-x

5. McLain RF (2004) Functional outcomes after surgery for spinal fractures: return to work and activity. Spine (Phila Pa 1976) 29:470-477 (discussion Z476)

6. Gelb D, Ludwig S, Karp JE, Chung EH, Werner C, Kim T, Poelstra K (2010) Successful treatment of thoracolumbar fractures with short-segment pedicle instrumentation. J Spinal Disord Tech 23:293-301. doi:10.1097/BSD.0b013e3181af20b6

7. Korovessis P, Mpountogianni E, Syrimpeis V (2016) Percutaneous pedicle screw fixation plus kyphoplasty for thoracolumbar fractures A2, A3 and B2. Eur Spine J Off Publ Eur Spine Soc Eur Spinal Deform Soc Eur Sec Cerv Spine Res Soc. doi:10.1007/ s00586-016-4743-6

8. McAnany SJ, Overley SC, Kim JS, Baird EO, Qureshi SA, Anderson PA (2016) Open versus minimally invasive fixation techniques for thoracolumbar trauma: a meta-analysis. Glob Spine J 6:186-194. doi:10.1055/s-0035-1554777

9. Stavridis SI, Bucking P, Schaeren S, Jeanneret B, Schnake KJ (2010) Implant removal after posterior stabilization of the thoraco-lumbar spine. Arch Orthop Trauma Surg 130:119-123. doi:10.1007/s00402-009-0962-1

10. Jeon CH, Lee HD, Lee YS, Seo JH, Chung NS (2015) Is it beneficial to remove the pedicle screw instrument after successful posterior fusion of thoracolumbar burst fractures? Spine (Phila Pa 1976) 40:E627-E633. doi:10.1097/brs.0000000000000870

11. Andress HJ, Braun H, Helmberger T, Schurmann M, Hertlein H, Hartl WH (2002) Long-term results after posterior fixation of thoraco-lumbar burst fractures. Injury 33:357-365

12. Wild A, Pinto MR, Butler L, Bressan C, Wroblewski JM (2003) Removal of lumbar instrumentation for the treatment of recurrent low back pain in the absence of pseudarthrosis. Arch Orthop Trauma Surg 123:414-418. doi:10.1007/s00402-003-0561-5

13. Kim HJ, Kang KT, Moon SH, Chun HJ, Kim HS, Park JO, Moon ES, Kim BR, Sohn JS, Lee HM (2011) The quantitative assessment of risk factors to overstress at adjacent segments after lumbar fusion: removal of posterior ligaments and pedicle screws. Spine (Phila Pa 1976) 36:1367-1373. doi:10.1097/BRS. 0b013e318221a595

14. Deckey JE, Court C, Bradford DS (2000) Loss of sagittal plane correction after removal of spinal implants. Spine (Phila Pa 1976) 25:2453-2460

15. Potter BK, Kirk KL, Shah SA, Kuklo TR (2006) Loss of coronal correction following instrumentation removal in adolescent idiopathic scoliosis. Spine (Phila Pa 1976) 31:67-72

16. Kim SW, Ju CI, Kim CG, Lee SM, Shin H (2008) Efficacy of spinal implant removal after thoracolumbar junction fusion. J Korean Neurosurg Soc 43:139-142. doi:10.3340/jkns.2008.43. 3.139

17. Jentzsch T, Gomes de Lima V, Seifert B, Sprengel K, Werner CML (2015) The benefits of elective spinal implant removal: a retrospective study of 137 patients. Eur Spine J 25:856-864. doi:10.1007/s00586-015-4211-8

18. Ko SB, Lee SW (2014) Result of posterior instrumentation without fusion in the management of thoracolumbar and lumbar unstable burst fracture. J Spinal Disord Tech 27:189-195

19. Vaccaro AR, Oner C, Kepler CK, Dvorak M, Schnake K, Bellabarba C, Reinhold M, Aarabi B, Kandziora F, Chapman J, Shanmuganathan R, Fehlings M, Vialle L, Injury AOSC, Trauma Knowledge F (2013) AOSpine thoracolumbar spine injury classification system: fracture description, neurological status, and key modifiers. Spine (Phila Pa 1976) 38:2028-2037. doi:10.1097/ BRS.0b013e3182a8a381

20. Roland M, Morris R (1983) A study of the natural history of back pain. Part I: development of a reliable and sensitive measure of disability in low-back pain. Spine (Phila Pa 1976) 8:141-144

21. Kuklo TR, Polly DW, Owens BD, Zeidman SM, Chang AS, Klemme WR (2001) Measurement of thoracic and lumbar fracture kyphosis: evaluation of intraobserver, interobserver, and technique variability. Spine (Phila Pa 1976) 26:61-65 (discussion 66)

22. McCormack T, Karaikovic E, Gaines RW (1994) The load sharing classification of spine fractures. Spine (Phila $\mathrm{Pa}$ 1976) 19:1741-1744

23. Velanovich V (2007) Behavior and analysis of 36-item ShortForm Health Survey data for surgical quality-of-life research. Arch Surg 142:473-477. doi:10.1001/archsurg.142.5.473 (discussion 478)

24. Aaronson NK, Muller M, Cohen PD, Essink-Bot ML, Fekkes M, Sanderman R, Sprangers MA, te Velde A, Verrips E (1998) Translation, validation, and norming of the Dutch language version of the SF-36 Health Survey in community and chronic disease populations. J Clin Epidemiol 51:1055-1068 
25. Soer R, Reneman MF, Speijer BL, Coppes MH, Vroomen PC (2012) Clinimetric properties of the EuroQol-5D in patients with chronic low back pain. Spine J 12:1035-1039. doi:10.1016/j.spi nee.2012.10.030

26. Agota Szende BJ, Cabases Juan (2014) Self-reported population health: an international perspective based on EQ-5D. Springer, Netherlands

27. Wang XY, Dai LY, Xu HZ, Chi YL (2008) Kyphosis recurrence after posterior short-segment fixation in thoracolumbar burst fractures. J Neurosurg Spine 8:246-254. doi:10.3171/SPI/2008/8/ $3 / 246$

28. Stadhouder A, Buckens CF, Holtslag HR, Oner FC (2010) Are existing outcome instruments suitable for assessment of spinal trauma patients? J Neurosurg Spine 13:638-647. doi:10.3171/ 2010.5.SPINE09128

29. Oner FC, Sadiqi S, Lehr AM, Aarabi B, Dunn RN, Dvorak MF, Fehlings MG, Kandziora F, Post MW, Rajasekaran S, Vialle L, Vaccaro AR (2015) Toward developing a specific outcome instrument for spine trauma: an empirical cross-sectional multicenter ICF-based study by AOSpine Knowledge Forum Trauma. Spine (Phila Pa 1976) 40:1371-1379. doi:10.1097/BRS. 0000000000001009

30. Siebenga J, Leferink VJ, Segers MJ, Elzinga MJ, Bakker FC, Ten DH, Rommens PM, Patka P (2008) A prospective cohort study comparing the VAS spine score and Roland-Morris disability questionnaire in patients with a type A traumatic thoracolumbar spinal fracture. Eur Spine J Off Publ Eur Spine Soc Eur Spinal Deform Soc Eur Sect Cerv Spine Res Soc 17:1096-1100. doi:10. 1007/s00586-008-0705-y

31. Knop C, Fabian HF, Bastian L, Blauth M (2001) Late results of thoracolumbar fractures after posterior instrumentation and transpedicular bone grafting. Spine (Phila Pa 1976) 26:88-99

32. Reinhold M, Knop C, Beisse R, Audige L, Kandziora F, Pizanis A, Pranzl R, Gercek E, Schultheiss M, Weckbach A, Buhren V, Blauth M (2010) Operative treatment of 733 patients with acute thoracolumbar spinal injuries: comprehensive results from the second, prospective, Internet-based multicenter study of the Spine Study Group of the German Association of Trauma Surgery. Eur Spine J Off Publ Eur Spine Soc Eur Spinal Deform Soc Eur Sect Cerv Spine Res Soc 19:1657-1676. doi:10.1007/s00586-0101451-5

33. Scheer JK, Bakhsheshian J, Fakurnejad S, Oh T, Dahdaleh NS, Smith ZA (2015) Evidence-based medicine of traumatic thoracolumbar burst fractures: a systematic review of operative management across 20 years. Glob Spine J 5:73-82. doi:10.1055/s0034-1396047

34. Whitehead L (2011) Methodological issues in Internet-mediated research: a randomized comparison of internet versus mailed questionnaires. J Med Internet Res 13:e109. doi:10.2196/jmir. 1593 